\title{
Something is in the wrong place.
}

Leonardo Rufino Garcia ${ }^{1}$, Andre Garzesi ${ }^{1}$, Elvis Porto $^{1}$, Diego Pretel ${ }^{1}$, Antonio Martins ${ }^{1}$, Marcone Sobreira $^{1}$, Flavio Brito ${ }^{1}$, and Marcello Felicio ${ }^{1}$

${ }^{1}$ Universidade Estadual Paulista Júlio de Mesquita Filho Câmpus de Botucatu Faculdade de Medicina

September 24, 2021

\begin{abstract}
Inferior vena cava filter (IVCF) embolization is not uncommon and can reach $11,8 \%$. However, device migration to the heart is not frequent and occurs in cases after IVCF fracture. We show the case of a young woman who was submitted to an unremarkable IVCF placement three days before and presented with hemodynamic instability. Since the device was not retrievable, the surgical team opted for an open cardiac surgery under cardiopulmonary bypass to remove IVCF.
\end{abstract}

\section{Something is in the wrong place.}

Vena cava filter misplacement.

Leonardo Rufino Garcia, $\mathrm{MD}^{1}$

André Monti Garzesi, MD ${ }^{1}$

Elvis Aaron Porto, $\mathrm{MD}^{1}$

Diego Pretel, $\mathrm{MD}^{1}$

Antonio Sérgio Martins, $\mathrm{MD}, \mathrm{PhD}^{1}$

Marcone Lima Sobreira, MD, $\mathrm{PhD}^{1}$

Flavio de Souza Brito, $\mathrm{MD}, \mathrm{PhD}^{1}$

Marcello Laneza Felicio, MD, $\mathrm{PhD}^{1}$

1.Department of Surgery, Universidade Estadual Paulista - UNESP, Botucatu, SP, Brazil

Corresponding author:

Leonardo Rufino Garcia, MD.

Department of Surgery, Universidade Estadual Paulista - UNESP

Av. Mário Rubens Guimarães Montenegro, Botucatu, SP, Brazil

$55143880-1547$

Zip Code 18618-687

lrufinogarcia@gmail.com

Word count: 494

We declare no financial support. 
Patient has signed informed consent.

International Review Board/ Clinical Trial Registration: N/A

Patients with venous thromboembolism and absolute contraindication to anticoagulation may benefit from inferior vena cava filter (IVCF) placement ${ }^{1,2}$. These devices can be permanent or retrievable. Complications associated with its placement are well known and more common with not retrieved devices ${ }^{3}$.

In this way, we show a case of a 47-year-old woman, in follow-up with gynecology because of abnormal uterine bleeding due to uterine myomatosis. Three days after IVCF implantation because of previous deep vein thrombosis she presented with tachycardia, hypotension, and hemodynamic instability. After chest tomography to confirm the hypothesis of pulmonary thromboembolism, the medical team verified that the device had migrated to the right atrium (fig.1A), with punctual perforation (fig.1B).

She underwent cardiac surgery with medium sternotomy, bicaval cannulation, and cardiopulmonary bypass for device resection via right atriotomy. Large clots and the filter were removed (fig.1C). The patient was weaned from cardiopulmonary bypass and is currently in postoperative recovery. In figure 1D we can see the vena cava filter with some clots after removal. Assistant physicians must keep in mind this potentially fatal complication, particularly when filter retrieval is not feasible.

\section{Disclosure/ Conflict of interest and funding}

Brito FS receives personal fees from Novartis, Servier, Merck, Astra Zeneca and Bayer.

Sobreira $M L$ is speaker to Sanofi, Bayer and Pfizer.

There is no funding to report.

\section{Author contributions :}

Leonardo Rufino Garcia: Concept/design, data analysis/interpretation, drafting article, critical revision of article, approval of article, data collection.

André Monti Garzesi: Concept/design, data analysis/interpretation, drafting article, critical revision of article, approval of article, data collection.

Elvis Aaron Porto: Drafting article, critical revision of article, approval of article.

Diego Pretel: Drafting article, critical revision of article, approval of article.

Antonio Sérgio Martins: Concept/design, data analysis/interpretation, critical revision of article, approval of article.

Marcone Lima Sobreira: Concept/design, data analysis/interpretation, critical revision of article, approval of article, data collection.

Flavio de Souza Brito: Concept/design, drafting article, critical revision of article, approval of article.

Marcello Laneza Felicio: Concept/design, drafting article, critical revision of article, approval of article.

\section{References}

1. Marron RM, Rali P, Hountras $\mathrm{P}$ et al . Inferior Vena Cava Filters: Past, Present, and Future. Chest 2020;158(6):2579-89.

2. Holly BP, Funaki B, Lessne ML. Inferior Vena Cava Filters: Why, Who, and for How Long? Clin Chest Med 2018;39(3):645-50.

3. Girard P, Meyer G. The vena cava filter mystery and misery. Thromb Res 2017;153:129-31. 

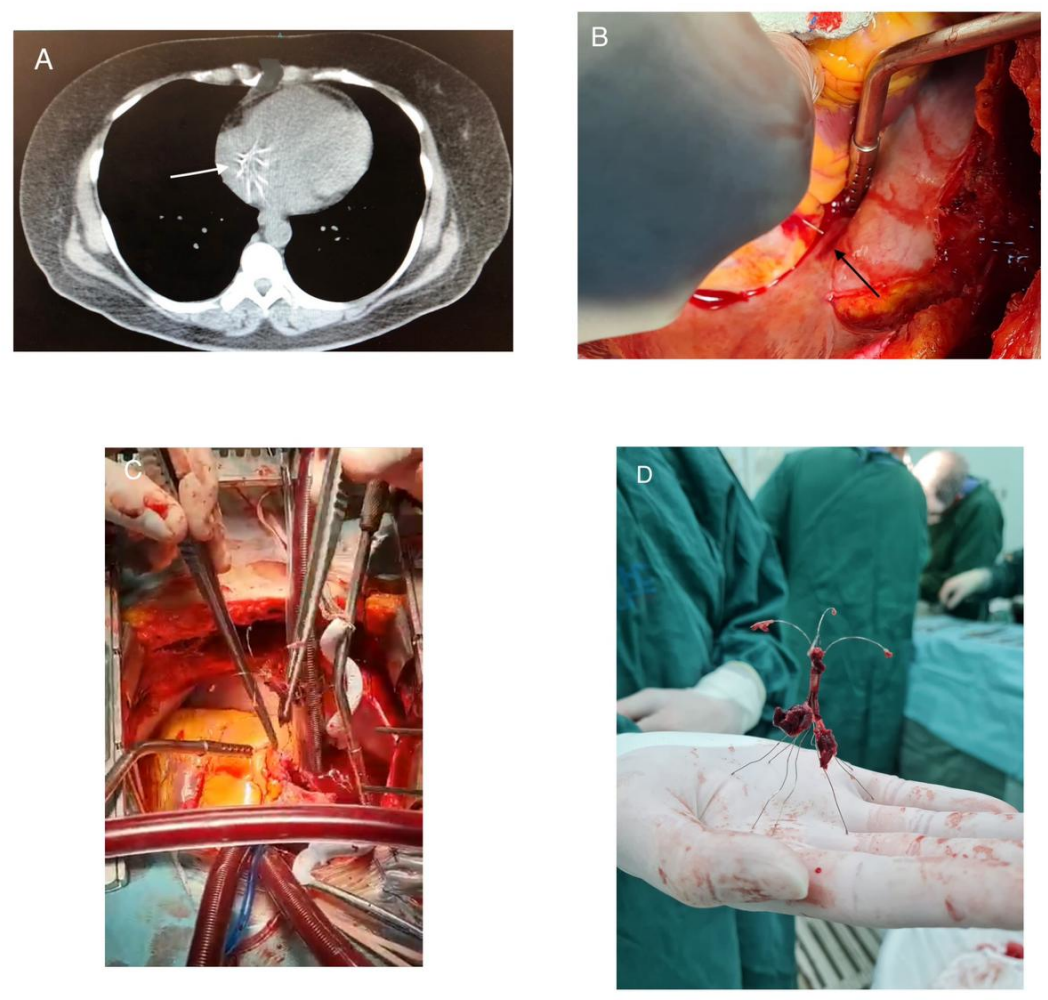